\title{
Extraocular Motor Unit and Whole-Muscle Responses in the Lateral Rectus Muscle of the Squirrel Monkey
}

\author{
Stephen J. Goldberg, ${ }^{1}$ M. Alex Meredith, ${ }^{1}$ and Mary S. Shall ${ }^{2}$ \\ Departments of ${ }^{1}$ Anatomy and ${ }^{2}$ Physical Therapy, Virginia Commonwealth University, Medical College of Virginia, \\ Richmond, Virginia 23298-0709
}

Because primate studies provide data for the current experimental models of the human oculomotor system, we investigated the relationship of lateral rectus muscle motoneuron firing to muscle unit contractile characteristics in the squirrel monkey. Also examined was the correlation of whole-muscle contractile force with the degree of evoked eye displacement. A force transducer was used to record lateral rectus wholemuscle or muscle unit contraction in response to abducens whole-nerve stimulation or stimulation of single abducens motoneurons or axons. Horizontal eye displacement was recorded using a magnetic search coil.

(1) Motor units could be categorized based on contraction speed (fusion frequency) and fatigue. (2) The kt value (change in motoneuronal firing necessary to increase motor unit force by $1.0 \mathrm{mg}$ ) of the units correlated with maximum tetanic tension. (3) There was some tendency for maximum tetanic tension of

Eye movements have been extensively examined in primates, and a number of system models have been based on neuronal firing patterns in relation to measures of eye movements in alert animals. Numerous investigators have studied the firing patterns of extraocular motoneurons, surrounding reticular formation cells and other higher center neurons that serve to generate precise and repeatable saccades, pursuit, and fixations (Robinson, 1981; Fuchs et al., 1985; Sparks, 1986; Goldberg and Segraves, 1989; Dean, 1996; Moschovakis et al., 1996). At the extraocular periphery, the transformation from motoneuron firing to eye position is often considered to be a simple linear function (Keller, 1981; Fuchs et al., 1988) as motor units are recruited into action and firing frequencies change to adjust force. However, to our knowledge, the contractile characteristics of primate extraocular motor units have not been investigated.

In contrast, although central oculomotor control has not been studied with the same intensity in cat as in primate, the contractile characteristics of cat extraocular muscles and motor units have been extensively examined (Lennerstrand, 1974a; Goldberg, 1990). Recent motor unit studies in cat focused on issues relevant to our understanding of the "behaving" eye movement system in an attempt to bridge the gap between acute motor unit studies,

\footnotetext{
Received May 29, 1998; revised Sept. 24, 1998; accepted Sept. 24, 1998.

This work was supported by National Institutes of Health-National Eye Institute Grant EY11249. We thank S. M. Highstein for his advice on surgery and anesthesia. We thank Ying Guo and Mary Ellen White for their technical assistance and J. Ross McClung for critically reading this manuscript.

Correspondence should be addressed to Dr. Stephen J. Goldberg, Virginia Commonwealth University, Medical College of Virginia, Department of Anatomy, P.O. Box 980709, Richmond, VA 23298-0709.

Copyright (C) 1998 Society for Neuroscience 0270-6474/98/1810629-11\$05.00/0
}

this unit population to separate into three groups. (4) At a constant frequency of $100 \mathrm{~Hz}, 95 \%$ of the motor units demonstrated significantly different force levels dependent on immediately previous stimulation history (hysteresis). (5) A mean force change of $0.32 \mathrm{gm} /{ }^{\circ}$ and a mean frequency change of 4.7 $\mathrm{Hz} /{ }^{\circ}$ of eye displacement were observed in response to wholenerve stimulation.

These quantitative data provide the first contractile measures of primate extraocular motor units. Models of eye movement dynamics may need to consider the nonlinear transformations observed between stimulation rate and muscle tension as well as the probability that as few as two to three motor units can deviate the eye $1^{\circ}$.

Key words: extraocular; eye movement; abducens; motoneuron; monkey; oculomotor muscle morphology, and motoneuron activation in the alert animal. First, as in spinal cord motor units, speed- and fatigue-based criteria (Burke et al., 1973; Burke, 1981) were used to separate extraocular motor units into five functional categories (Shall and Goldberg, 1992, 1995; Shall et al., 1996) that are numerically similar to the five or six anatomically determined muscle fiber types that have been proposed for extraocular muscle (Spencer and Porter, 1988).

Second, the change in single motoneuronal firing needed to increase motor unit force by $1.0 \mathrm{mg}$ (kt value) was explored (Shall and Goldberg, 1992; Shall et al., 1996). High kt value units were generally weak, low kt value units were generally powerful, and the possible relation between $\mathrm{kt}$ value and motoneuron $\mathrm{K}$ value (the change in motoneuron firing as alert animals fixated targets in $1^{\circ}$ increments) (Keller, 1981; Delgado-Garcia et al., 1986; Fuchs et al., 1988) will be considered in the Discussion.

Third, muscle force inequalities at identical frequencies of stimulation but with dissimilar stimulation histories ("hysteresis") (Binder-MacLeod and Clamann, 1989; Binder-MacLeod and Barrish, 1992; Shall et al., 1996) were examined. The percentage difference in motor unit force hysteresis (in cat) was greater than the percentage difference in motoneuron firing rate (in primate) (Eckmiller, 1974) as primary eye position was reached from different directions (Goldstein and Robinson, 1986).

Finally, the summation of motor unit tensions was examined when approximately five motor units were simultaneously activated (Goldberg et al., 1997b). It was found that there were force decrements of $\simeq 50 \%$ in $\sim 25 \%$ of the motor units studied (i.e., some units did not summate linearly). It was suggested that with 
more units simultaneously active, as in normal eye movements, a greater percentage of units might show nonlinear summation.

The present study was designed to fill some of the gaps in our knowledge about the contractile properties of primate extraocular muscles. Because current models of eye movement control are based in the primate, these data are clearly germane to our understanding of this intricate and dynamic system in animals and in man.

Preliminary data have been presented in abstract form (Goldberg et al., 1997a, 1998).

\section{MATERIALS AND METHODS}

All procedures for the care and use of monkeys complied with the United States Public Health Service Policy on Humane Care and Use of Laboratory Animals, and were approved by the Institutional Animal Care and Use Committee at Virginia Commonwealth University. All procedures were performed under deep surgical anesthesia and are similar to those previously performed in the cat (Shall and Goldberg, 1992; Shall et al., 1996; Goldberg and Shall, 1997).

Surgical preparation. Six adult male squirrel monkeys (Saimiri sciureus, $0.7-1.1 \mathrm{~kg}$ ) were used. Monkeys were premedicated with $15 \mathrm{mg} / \mathrm{kg}$ ketamine, $0.1 \mathrm{mg} / \mathrm{kg}$ acepromazine, and $10 \mathrm{mg} / \mathrm{kg}$ glycopyrrolate, all administered intramuscularly. The animals were then anesthetized with $2.0 \%$ isoflurane. While under isoflurane, the animals were given sodium pentobarbital $(15 \mathrm{mg} / \mathrm{kg}$, i.p.), and the gas anesthesia was discontinued. Supplemental doses of sodium pentobarbital were provided intravenously to maintain deep surgical anesthesia as assessed by the absence of blink reflexes and withdrawal to digit pinch. A tracheostomy was performed, and body temperature was maintained at $37^{\circ} \mathrm{C}$ with a heating pad. The monkeys' EKG, end-tidal $\mathrm{CO}_{2}$, and respiratory rate were continuously monitored, again to insure deep anesthesia and to maintain normal vital signs. An intravenous drip of lactated Ringer's solution with $5 \%$ dextrose was also provided.

The animal was placed in a Kopf stereotaxic frame. A midline incision was made from the forehead to the back of the neck. In two of the six animals a bilateral, posterior parietal craniotomy was performed, and the occipital cortex and cerebellum were aspirated. The floor of the fourth ventricle was thus exposed to see the facial colliculus and, thereby, localize the abducens nucleus. An anterior parietal craniotomy was performed in all animals to facilitate placement of a bipolar electrode used to stimulate the abducens nerve in the brainstem (coordinates: anterior $1.5 \mathrm{~mm}$, lateral $2.0 \mathrm{~mm}$, depth $6.0 \mathrm{~mm}$ ) (Emmers and Akert, 1963). We approached the nerve coordinates at an angle of $65^{\circ}$ from the vertical. The temporalis muscle was retracted, the lateral bony orbit was removed, and the lateral rectus muscle and its tendon were exposed. The muscle was kept warm and moist with mineral oil. Individual experiments could last as long as $15 \mathrm{hr}$ after which the animals were killed with an overdose of sodium pentobarbital.

In four of the six animals the posterior parietal craniotomy and occipital and cerebellar aspiration were not performed. All experimental procedures were performed using a stimulation electrode placed near the abducens nerve in the brainstem, with electrodes as described below.

Stimulation and recording techniques. In the first three animals the abducens nerve was stimulated with a stainless steel bipolar electrode ( $0.5 \mathrm{~mm}$ diameter and $2.0 \mathrm{~mm}$ between poles) with $\sim 1.0 \mathrm{~mm}$ of uninsulated surface at each tip. Optimal placement of the electrode was determined based on contractile responses of the lateral rectus muscle to nerve stimulation. The nerve was stimulated with a $0.1 \mathrm{msec}$ duration pulse $(400 \mu \mathrm{A})$ at $1.0 \mathrm{~Hz}$ to antidromically identify single motoneurons in the abducens nucleus of two of these animals (only whole-muscle data were taken on one animal). These neurons were located using glass micropipette electrodes $(1.0 \mu \mathrm{m}$ tip) filled with $1.6 \mathrm{M}$ potassium citrate. The resistance of these electrodes ranged from 10 to $30 \mathrm{M} \Omega$, and they were driven with a hydraulic microdrive into the area of the abducens nucleus (coordinates: posterior $2.0 \mathrm{~mm}$, lateral $1.0 \mathrm{~mm}$, depth $3.5 \mathrm{~mm}$ ) (Emmers and Akert, 1963). Identified single motoneurons were stimulated extracellularly with these electrodes to evoke contractions of single-muscle units in the lateral rectus muscle (Lennerstrand, 1974b; Goldberg and Shall, 1997).

In the remaining three animals a bipolar "brush" electrode was used to stimulate the whole-nerve or single-muscle fibers within the nerve. Each pole of the brush electrode was constructed in the following manner. Nine insulated stainless steel wires $[25 \mu \mathrm{m}$ diameter, often used for electromyographic (EMG) recordings] were inserted into a single 22 gauge stainless steel tube (10 cm long), and the entire structure was sealed with an insulating material (InsL-X). The wire brush was cut with a scissors so that $\sim 2.0 \mathrm{~mm}$ extended beyond the end of the stainless steel tube. This short extension insured the rigidity of the electrode and exposed the wires at the tip only. The wires on the other end of the tube were soldered to miniature nine pin connectors. The insulated tubes with their brush electrodes were then glued together with InsL-X so that there was $2.0 \mathrm{~mm}$ between poles. This electrode enabled us to stimulate between each nine wire pole so that the electrode could operate as a "standard" bipolar electrode with each pole being $\sim 225 \mu \mathrm{m}$ in diameter. The whole abducens nerve was activated in this way. Alternatively, we could stimulate between any two of the 18 single brush wires with varying intensity to activate single axons within the nerve.

The responses of the lateral rectus muscle to stimulation of the whole abducens nerve were recorded as follows. A scleral search coil consisting of induction coils sutured to the sclera after the method of Judge et al. (1980) was used to measure eye movement. The animal, with the scleral search coil in place, was positioned in the center of a magnetic coil frame (1.0 m diameter). Output from the scleral coil was routed to an amplifier (Remmel, 1980) with a sensitivity to scleral coil displacement equivalent to $\sim 0.5^{\circ}$. Amplified signals were sent to an oscilloscope where the vertical and horizontal components of eye position were displayed. These data were also routed to a digital tape recorder for later analysis. For calibration, a $3.0 \mathrm{~mm}$ reflective disk was placed on the cornea on which a fiber-optic light was focused and reflected onto a tangent screen. Any movement of the eye was accompanied by a corresponding movement of the reflected spot on the screen. The abducens nerve was stimulated over a range of predetermined tetanic frequencies $(200 \mathrm{msec}$ duration tetanic trains) to produce a range of horizontal ocular excursions, all starting from primary position. The voltage output obtained from the scleral search coil was calibrated with the angular displacement of the reflected spot. To correlate stimulation frequency and amplitude of ocular displacement with tension generation, the following procedure was also necessary.

To measure the tension produced by stimulation of the abducens nerve from an intact lateral rectus muscle, a 5-0 silk thread was looped under the tendon of the muscle at its scleral attachment. The tendon, however, remained intact and attached to the globe (Goldberg and Shall, 1997). The other end of the loop of thread was attached to a strain gauge (Pixie model 8108, Endevco; natural frequency of $2.0 \mathrm{kHz}$ and a compliance of $\sim 2 \mu \mathrm{m} / \mathrm{gm}$ ). The strain gauge carrier (mounted on the stereotaxic frame) was manipulated to tighten the thread and bring the muscle to optimal length for the largest isometric twitch tension when the abducens nerve was stimulated. Lateral rectus muscle position to assess maximum tetanic tension has been shown to be the same as that for single twitch stimulation (Barmack et al., 1971). Identical stimulation current and frequencies were used during the previous eye movement measurement procedure and this tension measurement procedure. By combining these two techniques, we were able to determine the relationship between stimulation frequency, muscle tension, and degree of ocular excursion. We insured that we stimulated the entire abducens nerve to elicit whole-muscle responses in the following manner. We found that a stimulation intensity of $\sim 400 \mu \mathrm{A}$ elicited maximal twitches. Reduction of that intensity yielded smaller twitches, whereas increased stimulation intensity did not evoke larger responses, showing that the whole nerve was already being activated. We routinely stimulated at $\sim 200 \mu \mathrm{A}$ above the intensity that yielded a maximum response (supramaximal stimulation) to insure consistent whole-nerve activation. Similar procedures have been used by us (Meredith and Goldberg, 1986; Nelson et al., 1986; Shall and Goldberg, 1992; Goldberg and Shall, 1997) and others (Cooper and Eccles, 1930; Barmack et al., 1971; Waldeck et al., 1995) in the cat, and whole extraocular muscle responses were comparable among the studies.

Two stainless steel wires ( $25 \mu \mathrm{m}$ diameter) were inserted (through a 28 gauge needle), from dorsal to ventral, into the proximal and distal ends of the lateral rectus muscle to record both whole-muscle and singlemuscle unit EMG potentials (Shall and Goldberg, 1995). The wires were $\sim 5.0 \mathrm{~mm}$ apart and were used as a bipolar EMG electrode (Shall and Goldberg, 1995) in this relatively small muscle (observed to be approximately one-third the size of the cat's lateral rectus muscle). On-line analysis of the EMG response in the last three animals insured that we stimulated single axons within the abducens nerve with our brush electrode. Very low intensity stimulation $(10-50 \mu \mathrm{A})$ between two of the fine wires of the brush electrode often evoked twitch contractions of the 
muscle. Following the technique of Macefield et al. (1996), stimulation intensity was reduced until neither a contractile nor EMG response was evident. As the stimulation intensity was again raised we observed a simultaneous contractile and EMG response. Usually, continued increases in stimulation intensity, within a wide range, did not evoke larger contractile or altered EMG potentials. Once this high-intensity range was exceeded we did note larger contractions and generally larger or more complex EMG shapes. This indicated that more than one muscle unit was being activated. We stayed well within the "acceptable" range for each unit and continuously monitored the EMG response for alterations during all twitch and tetanic stimulation paradigms. In addition, changing the active poles within the brush electrode evoked different contractile and EMG responses, indicating that another single axon was being stimulated. Small changes $(50-100 \mu \mathrm{m})$ in electrode depth also provided new sites at which different units could be stimulated. A large number of motor units could be studied in this way in a single animal, and it greatly reduced the surgical risk. It should also be noted here that muscle units activated through stimulation of single motoneurons using micropipettes in the abducens nucleus showed similar contraction characteristics to those muscle units activated through axonal stimulation within the nerve using the brush electrode (see Results).

Stimulation paradigms. Whole-muscle and single motor unit mechanical properties were measured in response to $0.1-0.2 \mathrm{msec}$ duration rectangular stimuli applied through the nerve-stimulating electrodes or glass micropipette electrodes at various frequencies (Shall et al., 1996). All stimulation trains were delivered using a programmable pulse generator (AMPI Master-8). Whole-muscle and single-unit twitch contraction time (onset of force to peak force) and twitch tension were averaged over five contractions at $1 \mathrm{~Hz}$. Twitch potentiation is not noted at this frequency (Meredith and Goldberg, 1986; Nelson et al., 1986; Shall and Goldberg, 1992, 1995; Shall et al., 1995). The twitch measurements were made before tetanic stimulation to avoid potentiation.

Lateral eye movement excursion, whole-muscle, and motor unit tetanic tension were assessed as follows. Tetanic tension measurements were taken during a series of constant frequency, $200 \mathrm{msec}$ pulse trains at stimulation rates ranging from 50 to $300 \mathrm{~Hz}$ in $10 \mathrm{~Hz}$ increments. Delivery of each stimulation train was separated by $5 \mathrm{sec}$ intervals to ensure a return to baseline force. The maximum tetanic tension for each unit was seen at or about the fusion frequency of the unit. Fusion frequency was defined as the stimulation frequency at which individual twitches could not be resolved at the tension plateau. The kt value (Shall and Goldberg, 1992) was defined as the slope of the tetanic tension versus the stimulation rate from $50 \mathrm{~Hz}$ until fusion frequency of that individual motor unit. For example, a motor unit kt value of 1.5 would indicate that a frequency change of $1.5 \mathrm{~Hz}$ would increase the tension of the unit by $1.0 \mathrm{mg}$.

A pulse/step and fatigue assessment was done on single motor units only. Tension assessments were made during a series of $200 \mathrm{msec}$, pulse/step tetanic trains. Each stimulation train began with a $25 \mathrm{msec}$, high-frequency pulse phase ( $500 \mathrm{~Hz}$ for $10 \mathrm{msec}$ and $250 \mathrm{~Hz}$ for $15 \mathrm{msec}$ ) (Fuchs and Luschei, 1970), followed by a $175 \mathrm{msec}$ step phase in an attempt to mimic motoneuron discharge changes observed during saccades and subsequent fixations. Although the parameters of the initial pulse remained invariant from trial to trial, stimulus variation was incorporated into the later step phase with each successive tetanic trial. A regular increase in step frequency (Shall et al., 1996) was used. For example, the first trial began with the $25 \mathrm{msec}$ pulse followed by $175 \mathrm{msec}$ at $75 \mathrm{~Hz}$. The second trial began with the same pulse but now followed by $175 \mathrm{msec}$ at $90 \mathrm{~Hz}$. This then continued using $10 \mathrm{~Hz}$ increments per trial up to $200 \mathrm{~Hz}$. Tensions reached during the step phase were compared with those recorded in response to constant frequency stimulation, at $150 \mathrm{msec}$ after the start of either stimulation paradigm, to determine whether there was a tension hysteresis (Shall et al., 1996). We define hysteresis as a $5 \%$ or greater difference in tension in response to identical stimulation frequencies delivered with constant frequency stimulation or during the step phase of the pulse/step stimulation paradigm (Shall et al., 1996).

Resistance to fatigue was evaluated by a tetanic stimulation paradigm that incorporated a series of $150 \mathrm{~Hz}$ tetanic stimuli at a rate of one 500 msec train per second over a 2 min period (Shall and Goldberg, 1992, 1995). The fatigue index (FI) was determined for each motor unit examined by calculating the ratio of the tetanic tension measured during the final and initial cycles. Muscle units that showed $<60 \%$ of their initial tension were considered fatigable (Shall and Goldberg, 1992, 1995).

Data analysis. During the experiments all stimulus artifacts, motoneuron, EMG, and muscle responses were viewed on a storage oscilloscope and recorded on digital tape for subsequent quantitative analysis on a digital oscilloscope. The following single motor unit mechanical parameters were evaluated: twitch tension, twitch contraction time, maximum tetanic tension, fusion frequency, fatigue, and kt value. Motor unit twitch tension and twitch contraction time were averaged over a minimum of five responses. The motor units were grouped according to apparent

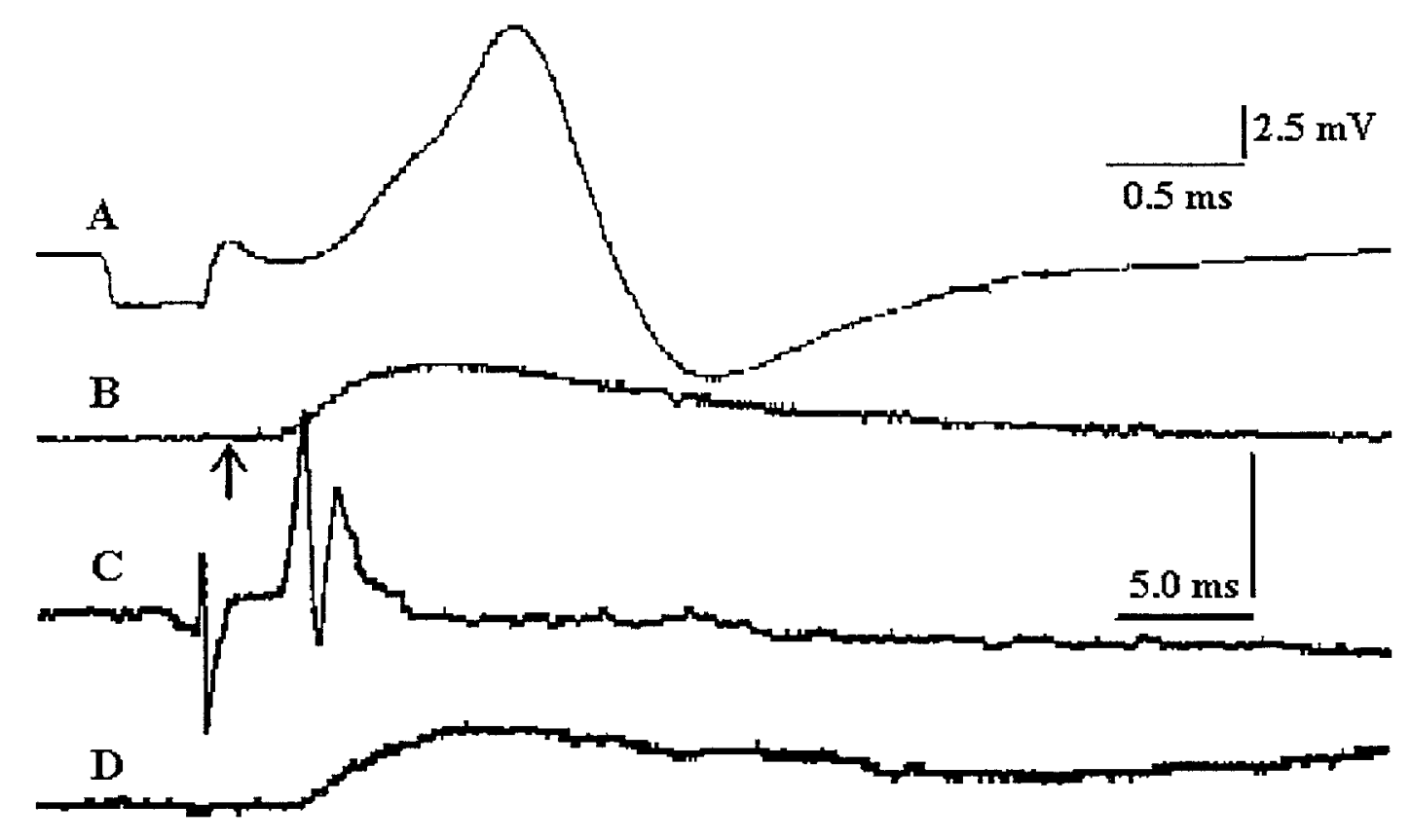

Figure 1. Motoneuron and muscle unit twitch response of one unit $(A, B)$ plus EMG and muscle unit twitch response $(C, D)$ of another unit. $A$, Antidromic response of a lateral rectus motoneuron to abducens nerve stimulation, extracellularly recorded. $B$, Single-muscle unit twitch in response to activation of motoneuron in $A$ through recording electrode (arrow indicates the time of the action potential of the cell; note different time scale). $C$, EMG response to stimulation of single abducens nerve axon with brush electrode. $D$, Simultaneously recorded single-muscle unit twitch response to axonal stimulation of same unit as in $C$. Calibration: $B-D, 5.0 \mathrm{msec}$ (horizontal bar); $B, D, 21.0 \mathrm{mg} ; C, 1.0 \mathrm{mV}$ (vertical bar). 

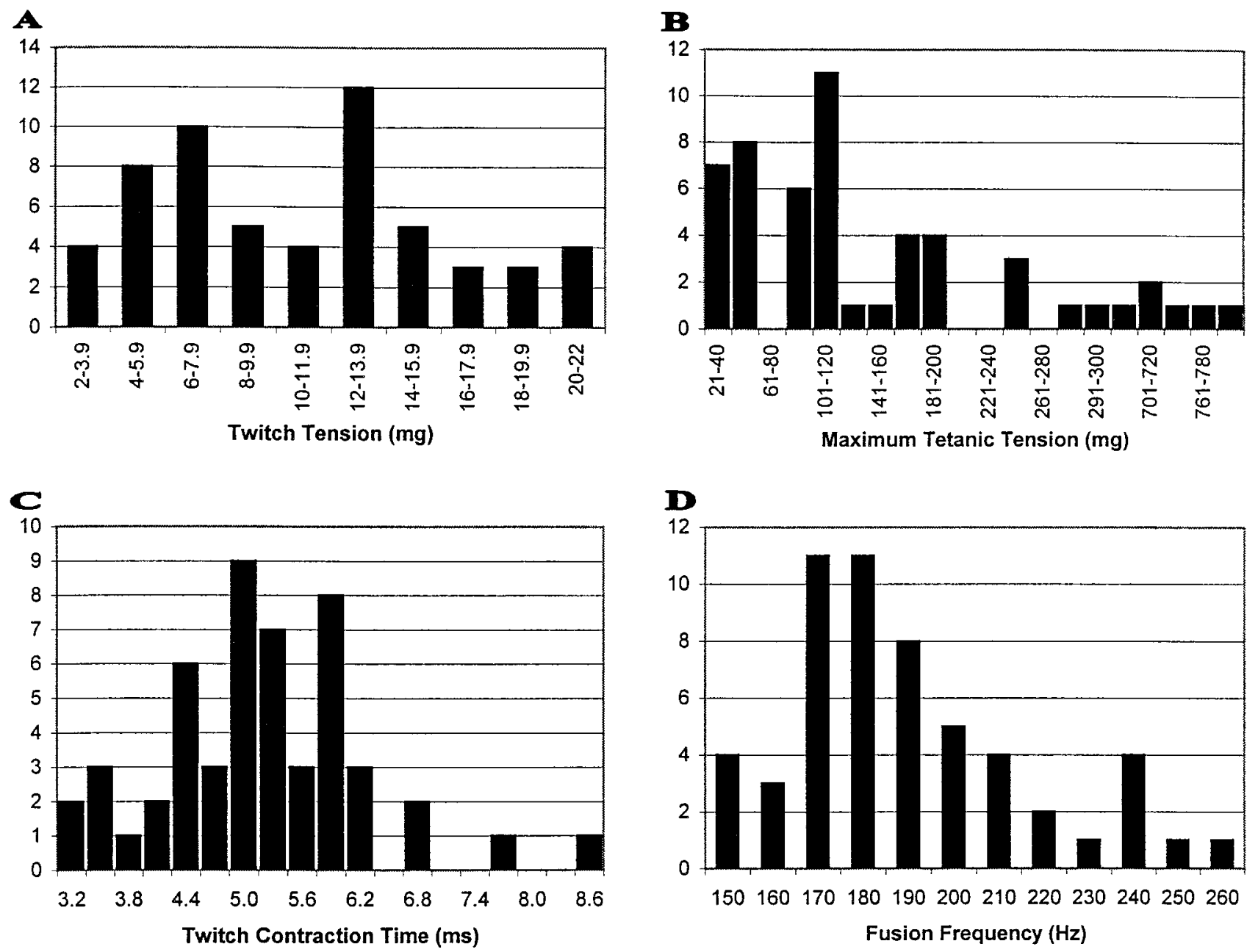

Figure 2. $A$, Twitch tension among 58 units $(\overline{\mathrm{x}}=10.7 \pm 5.02 \mathrm{SD}) . B$, Maximum tetanic tension among 53 units $(\overline{\mathrm{x}}=186.2 \pm 207.7 \mathrm{SD})$. $C$, Twitch contraction time among 58 units $(\overline{\mathrm{x}}=5.2 \pm 1.05 \mathrm{SD})$. $D$, Fusion frequency among 53 units $(\overline{\mathrm{x}}=190 \pm 24 \mathrm{SD})$.

similar mechanical characteristics and then analyzed by the Student's $t$ test (if there were two groups) or an ANOVA (for more than two groups) to test the null hypothesis that the sampled data means of the motor unit groups were equal.

\section{RESULTS}

\section{Motor unit contractile characteristics}

Figure 1 illustrates two single lateral rectus muscle units. Figure $1 A$ shows an antidromically identified motoneuron that was stimulated extracellularly through the recording pipette in the abducens nucleus to elicit a twitch contraction seen in Figure $1 B$ (Goldberg et al., 1976; Goldberg and Shall, 1997). Figure 1, $C$ and $D$, shows an electromyographic response and single-muscle unit twitch contraction of a different unit, elicited by stimulation of an abducens nerve axon with the brush electrode placed in the brainstem.

A total of 58 motor units were examined in five monkeys, although the fatigue test was not completed on all of those units. We found no significant difference between the muscle unit twitch contraction measures whether single motoneurons were stimulated in the abducens nucleus with glass micropipettes $(11.1 \pm 4.9$ $\mathrm{mg}$ tension and $5.0 \pm 0.8 \mathrm{msec}$ contraction time; $n=23$, two animals) or whether single abducens nerve axons were stimulated in the ventral brainstem with the brush electrode $(10.2 \pm 5.0 \mathrm{mg}$ and $5.4 \pm 1.2 \mathrm{msec} ; n=35$, three animals).
Figure 2 illustrates the distribution of contraction characteristics we observed. Twitch contraction time and tension, maximum tetanic tension (using constant frequency stimulation), and fusion frequency are shown. The distribution of unit tetanic tensions showed some tendency to separate into three groups (Fig. $2 B$ ): one group from 20 to $60 \mathrm{mg}$, another from 87 to $200 \mathrm{mg}$, and the last group exceeding $240 \mathrm{mg}$ of tetanic tension. Fusion frequency (Fig. 2D) showed a unimodal distribution, similar to the twitch tension (Fig. $2 A$ ) and twitch contraction time distributions (Fig. $2 C)$. Nevertheless, the units have been divided into fast $(\geq 190$ $\mathrm{Hz}$ ) and slow $(<190 \mathrm{~Hz})$ categories using the mean of $190 \mathrm{~Hz}$ (Shall and Goldberg, 1992; Shall et al., 1996). See the figure legend for unit numbers and other statistics.

Figure $3 A$ illustrates a scatter plot of the fatigue indices and fusion frequencies of the muscle unit population. Fatigue showed a bimodal distribution with 17 units classified here as "fatigable" (fatigue index $<0.6$ ) and 25 units as fatigue-resistant (fatigue index $\geq 0.8$ ). The combination of motor unit fusion frequency and fatigue was used to classify the units into four groups (Shall and Goldberg, 1992). The groups were: FF, fast fatigable (8); FR, fast fatigue-resistant (12); SF, slow fatigable (9); and S, slow fatigueresistant (13). Nontwitch (NT) units (Shall and Goldberg, 1992) were not observed in this study. Figure $5 B$ indicates that the faster units exhibited a wider range of maximum tetanic tensions, in- 


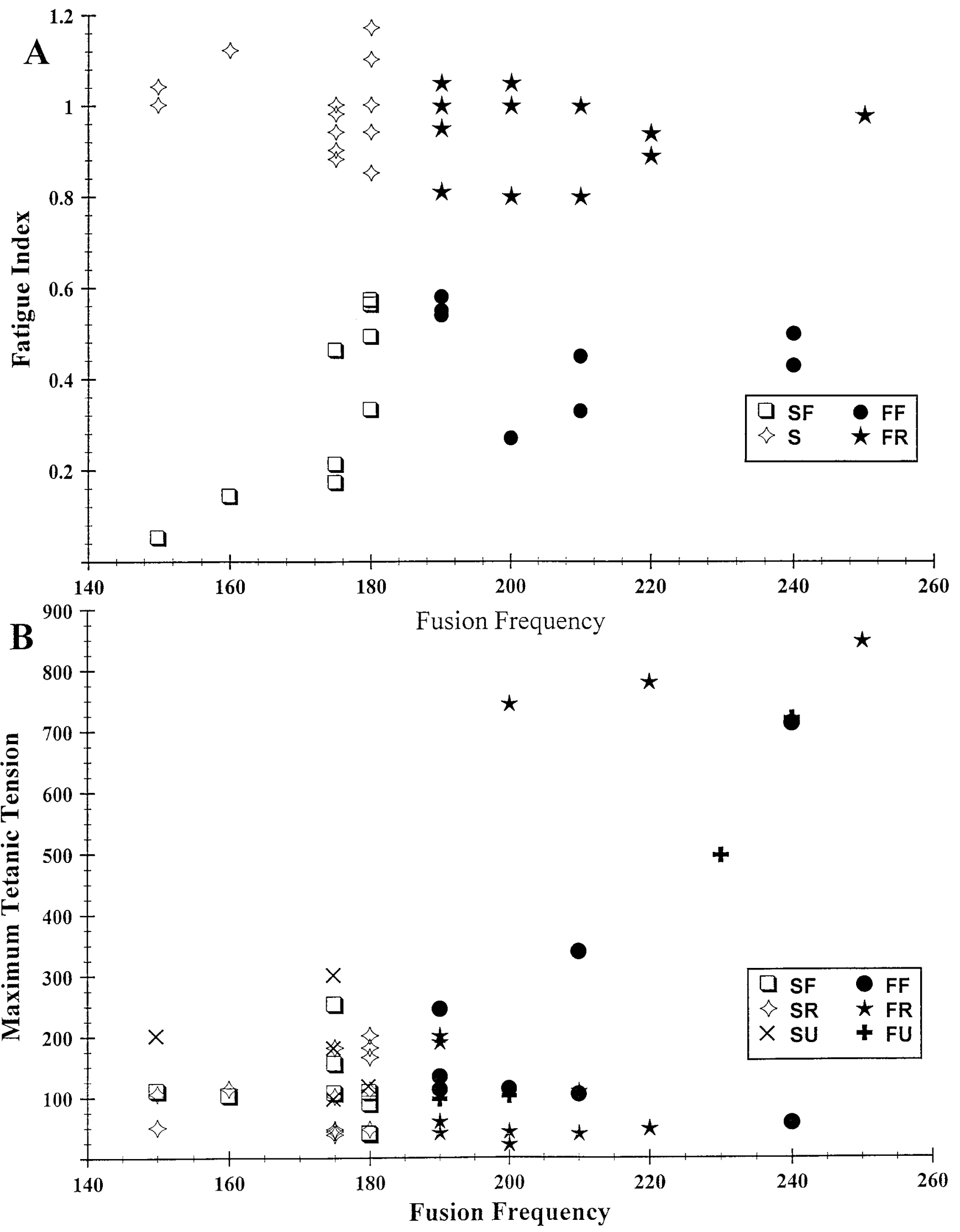

Figure 3. Graphs of fusion frequency versus fatigue index $(A)$ and maximum tetanic tension $(B) . F F$, Fast fatigable; $F R$, fast fatigue-resistant; $F U$, fast unclassified as to fatigue; $S F$, slow fatigable; $S$, slow; $S R$, slow fatigue-resistant; $S U$, slow unclassified as to fatigue. Legend also applies to Figures 4 and 5 . 


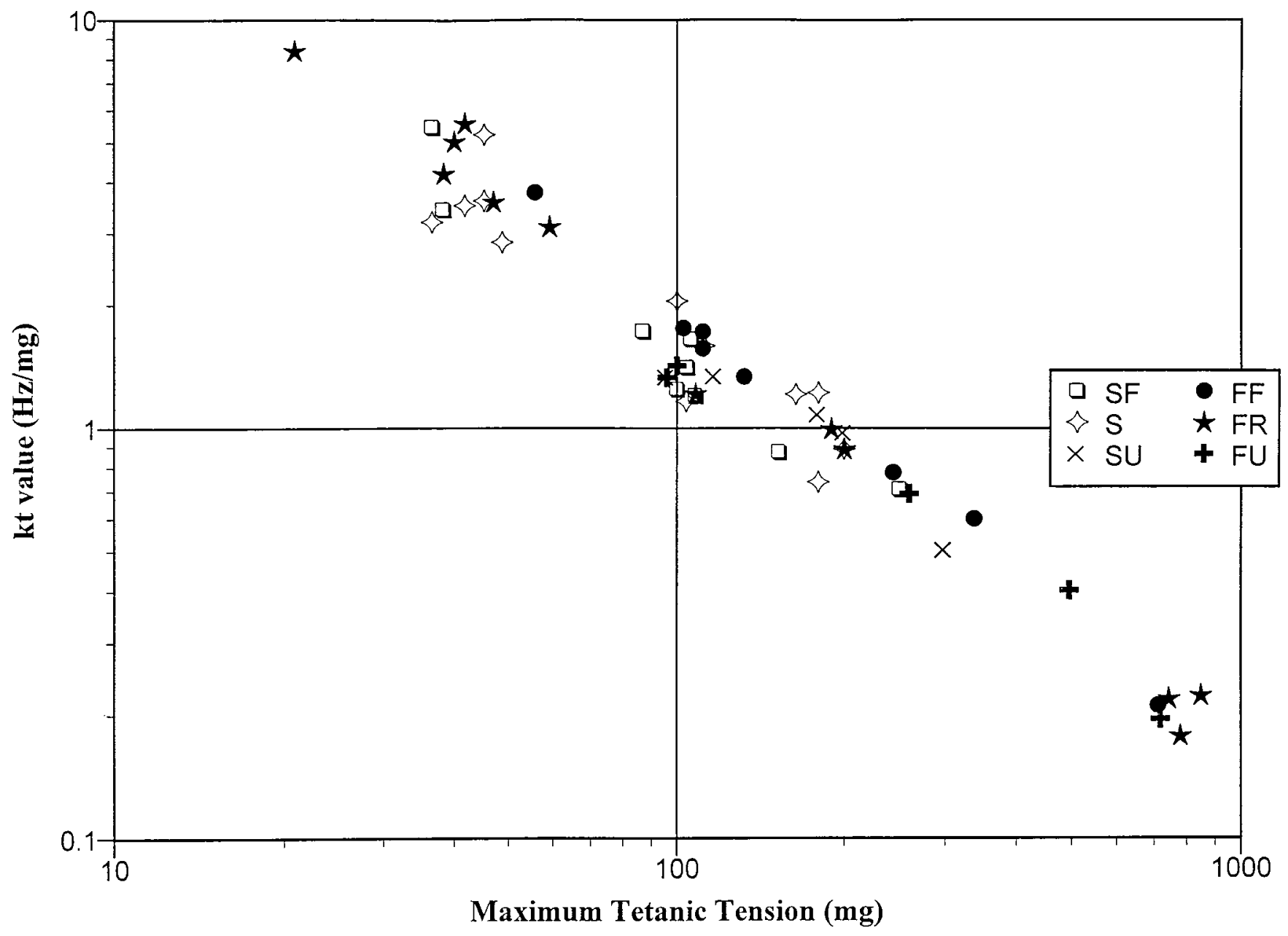

Figure 4. Log- $\log$ plot of muscle unit kt value (slope of the constant frequency stimulation rate from $50 \mathrm{~Hz}$ until fusion frequency vs the resultant forces) versus maximum tetanic tension $(r=0.99)$. Average kt value of all units $=1.93 \mathrm{~Hz} / \mathrm{mg}$.

cluding most of the more powerful units, than the slower units. However, both the weaker and more powerful units were mixed according to fatigue properties, as denoted by the symbols.

We have previously defined kt value as the slope of the relation between tetanic tension and series of constant frequency stimulation trains from $50 \mathrm{~Hz}$ up to fusion frequency (Shall and Goldberg, 1992). Figure 4 illustrates that relationship (log-log plot) in the present experiment. In general, more powerful units (maximum tetanic tensions $>240 \mathrm{mg}$ ) had lower $\mathrm{kt}$ values than the less powerful units and were, for the most part, fast units ( 9 of 11). Eleven of 14 of the weakest units (maximum tetanic tensions $<80 \mathrm{mg}$ ) were fatigue-resistant, although mixed according to contraction speed. In addition, there appeared to be an intermediate group of 27 units with mixed kt values, tensions, and fatigue properties.

The weaker units generally showed a wider range of step tension to constant frequency tension ratios (at $100 \mathrm{~Hz}$, Fig. 5A) than the more powerful units (Fig. $5 B$ ). In other words, hysteresis was greatest in the weaker units, and they were the most fatigueresistant as well. Fig. $5 C$ summarizes this data, and it can be seen that the more powerful units rarely exceed a step tension to constant frequency tension ratio of two.

Comparing all units for hysteresis, the tensions at the midrange firing frequency of $100 \mathrm{~Hz}$ were as follows. Seventy-five percent of the units had higher tensions (at $100 \mathrm{~Hz}$ ) after the pulse $(\overline{\mathrm{x}}=115.0 \pm 92.0 \mathrm{mg})$ than they did when stimulated with a constant frequency $(\overline{\mathrm{x}}=58.2 \pm 50.3 \mathrm{mg}$ ) (Fig. $5 A)$. In contrast, $20 \%$ of the units had higher tensions (at $100 \mathrm{~Hz}$ ) during constant frequency stimulation $(\overline{\mathrm{x}}=65.5 \pm 52.0 \mathrm{mg})$ than they did after the pulse $(\overline{\mathrm{x}}=37.8 \pm 35.0 \mathrm{mg})$. Five percent of the units did not show a difference between the two conditions (Fig. 5B) and consequently did not exhibit a tension hysteresis.

\section{Whole-muscle contractile characteristics}

We examined whole-muscle force characteristics in six animals and ocular displacement in four of those six animals. Both sets of measurements were done by recording the responses of the lateral rectus muscle to supramaximal stimulation of the whole abducens nerve in the brainstem. The average twitch tension of the whole muscle was $1.1 \pm 0.3 \mathrm{gm}$ with an average twitch contraction time of $6.0 \pm 0.8 \mathrm{msec}$. The average maximum tetanic tension was $13.7 \pm 2.6 \mathrm{gm}$ with an average fusion frequency of $232 \pm 46 \mathrm{~Hz}$.

Figure 6 illustrates how this information was collected. Wholemuscle tetanic tension and ocular displacement were recorded in response to a series of constant frequency stimulation trains. We first recorded ocular displacement using the reflective disk and/or search coil with the eye free, and then whole-muscle tension (Goldberg and Shall, 1997) was recorded in response to identical 

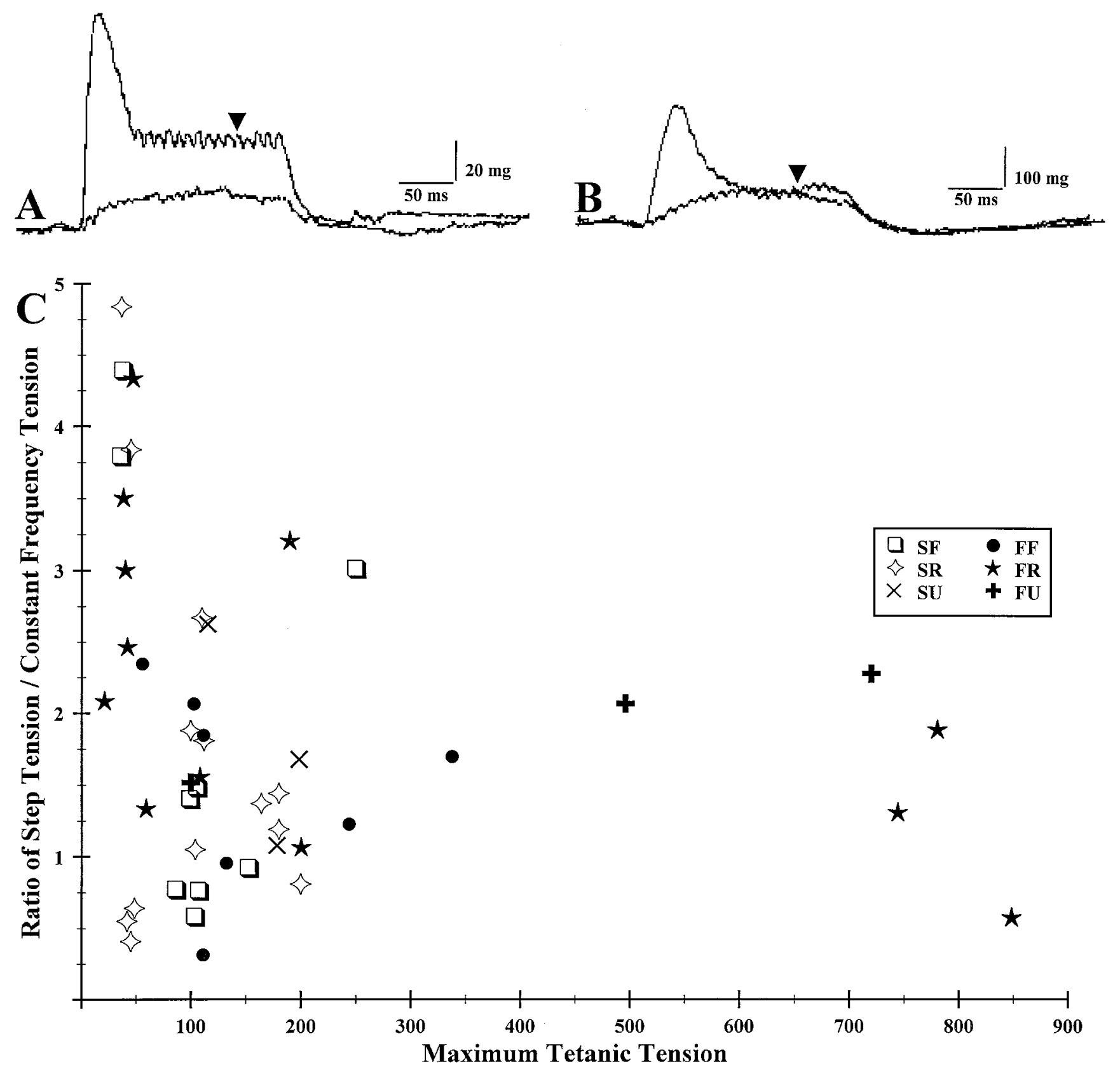

Figure 5. Muscle unit tetanic responses in a weak $(A)$ and a powerful $(B)$ unit. $A, 100 \mathrm{~Hz}$ constant frequency compared with $100 \mathrm{~Hz}$ step after $500 / 250$ $\mathrm{Hz}$ pulse starting at similar baselines. $B$, One hundred Hertz constant frequency compared with $100 \mathrm{~Hz}$ step after $500 / 250 \mathrm{~Hz}$ pulse starting at similar baselines. Arrows in $A$ and $B$ indicate the points at which tensions were compared. $C$, Maximum tetanic tension plotted against the ratio of step tension to constant frequency tension. Note that the weaker units tend to have higher ratios (greater hysteresis).

stimulation currents and frequencies (see Materials and Methods).

Figure $7 A$ shows ocular displacement as a function of tetanic tension, and Figure $7 B$ shows ocular displacement as a function of stimulation frequency. Grams per degree and frequency change per degree for each of the four animals are shown in conjunction with the plotted lines in Figure 7, $A$ and $B$, respectively. We saw an average force change of $0.32 \mathrm{gm} /{ }^{\circ}$ of ocular displacement and a $4.7 \mathrm{~Hz}$ frequency change per degree of ocular displacement among the animals.

These results on whole-muscle contraction and ocular displacement, when compared with the motor unit population results, suggest that two motor units $(\overline{\mathrm{x}}=186.2 \mathrm{mg}$ maximum tetanic tension) contracting maximally would be enough to move the eye $1^{\circ}$. In addition, the average $\mathrm{kt}$ value of all the units was 1.93, indicating that a tension increase of $1 \mathrm{mg}$ could be effected by an $\sim 2 \mathrm{~Hz}$ frequency change by an "average" unit.

\section{DISCUSSION}

The major findings regarding primate extraocular motor units in this study were as follows: (1) through the use of the bimodal fatigue distribution and the mean fusion frequency of the muscle units, the unit population could be separated into four categories (FF, FR, SF, and S); (2) the kt value of the units correlated with 


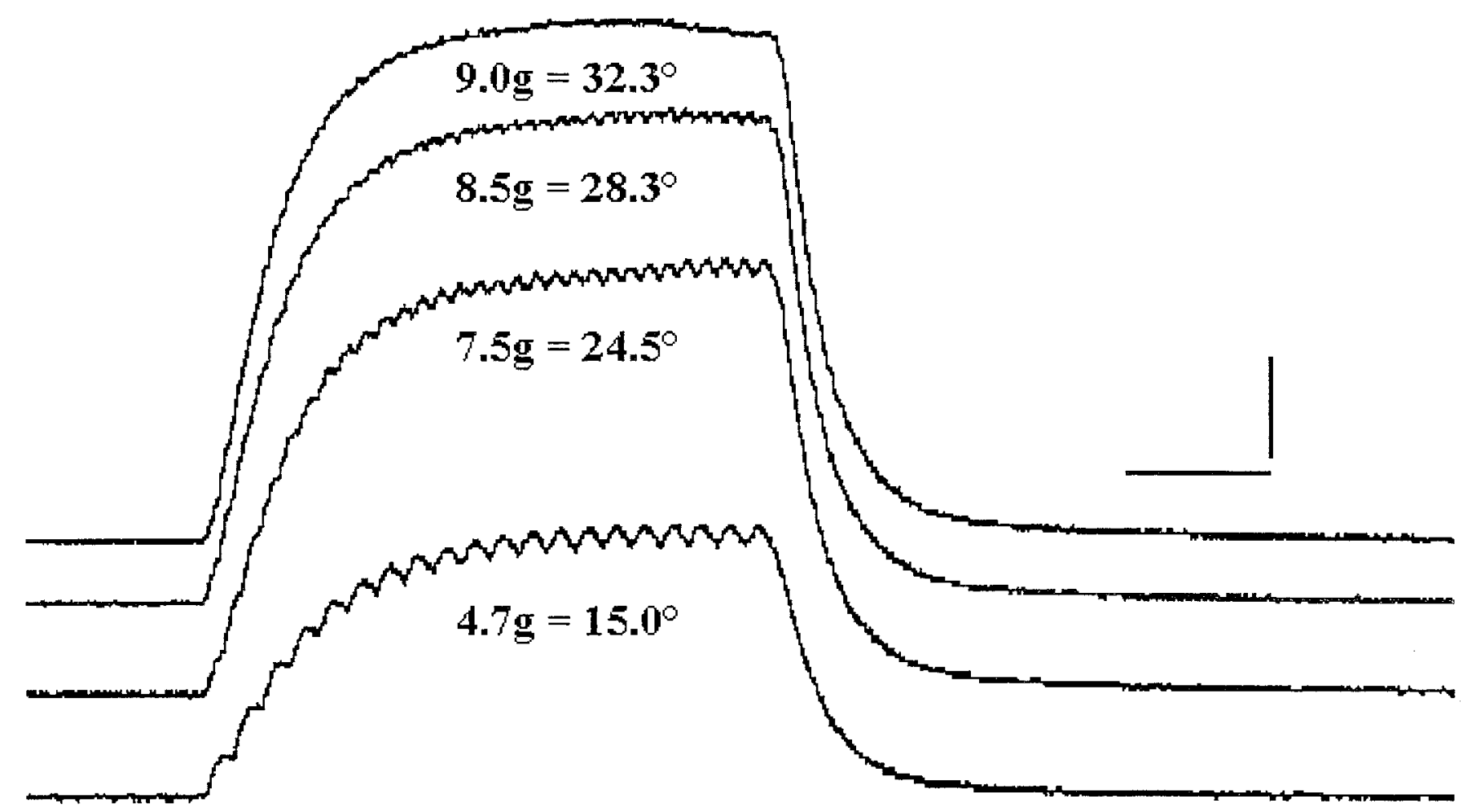

Figure 6. Whole lateral rectus muscle tetanic responses in grams. Degree of eye displacement is included for identical stimulation parameters in the same muscle. Constant frequency stimulation at 100,150,180, and $210 \mathrm{~Hz}$ from bottom to top. Calibration: 50 msec (horizontal bar), 1.84 gm (vertical bar).

maximum tetanic tension, and there was some tendency for maximum tetanic tension of this unit population to separate into three groups; and (3) the weaker motor units tended to show the greatest tension hysteresis and were also generally fatigue-resistant.

The major findings regarding primate whole-muscle force in relation to "eye movement" were that a force change of $0.32 \mathrm{gm} /{ }^{\circ}$ of ocular displacement and a frequency change of $4.7 \mathrm{~Hz} /{ }^{\circ}$ of ocular displacement were observed.

\section{Motor unit classification}

Motor unit classification schemes have traditionally used twitch contraction time (or fusion frequency) and fatigue to define unit groups (Burke et al., 1973; Lennerstrand, 1974a; Shall and Goldberg, 1992). These criteria also appear to be applicable to squirrel monkey motor units, although neither contraction time nor fusion frequency were clearly clustered, as in the cat (Shall and Goldberg, 1992). The mean fusion frequency (Shall and Goldberg, 1992) of $190 \mathrm{~Hz}$ was used to divide fast from slow units. The fatigue index did show a clear difference between groups; those units with a FI of $<0.6$ were classified as fatigable, and units with a FI $>0.8$ were classified as fatigue-resistant (Fig. 3). Only five units in the current study would be considered fatigable by the standards (FI $\leq 0.25$ ) applied in the hindlimb (Burke, 1981). Because glycogen depletion studies (Burke et al., 1973) have not been done, we can not directly correlate these physiological "types" with muscle fiber histochemistry or morphology (Spencer and Porter, 1988). It remains to be seen, then, whether a contraction speed and fatigue-based classification scheme for extraocular muscle (Shall and Goldberg, 1992) has relevance to functional properties, such as an order of recruitment, as has been shown for the limb musculature (Burke, 1981, 1990). Furthermore, recently found distinctions in myosin heavy chain isoforms that appear to show at least three types in extraocular muscle (Lucas and Hoh, 1997) may also need to be considered when comparing muscle unit structure-function relationships.

On the other hand, the weaker group of units was generally more fatigue-resistant and slower contracting than the more powerful group, not unlike hindlimb muscle units (Burke, 1981). The weaker group also displayed a greater degree of tension hysteresis than the more powerful group, and it responded to pulse stimulation with tensions much greater than maximum tetanic tension (as determined using constant frequency stimulation).

\section{Motor unit comparisons between monkey and cat}

The contraction time $(\overline{\mathrm{x}}=5.2 \mathrm{msec})$ and fusion frequency $(\overline{\mathrm{x}}=$ $190 \mathrm{~Hz}$ ) of squirrel monkey lateral rectus muscle motor units were faster than those seen in the cat $(\overline{\mathrm{x}}=6.6 \mathrm{msec}$ and $\overline{\mathrm{x}}=170 \mathrm{~Hz}$; Shall and Goldberg, 1992). Although the average twitch tension of squirrel monkey lateral rectus muscle units was weaker than in the cat $(\overline{\mathrm{x}}=10.7 \mathrm{mg}$ vs $\overline{\mathrm{x}}=30.9 \mathrm{mg})$, the difference in maximum tetanic tension was not great $(\bar{x}=186.2 \mathrm{mg}$ vs $\bar{x}=194.4 \mathrm{mg})$. The extraocular motor unit contractile forces and speeds we have reported in the cat (Nelson et al., 1986; Goldberg, 1990) were similar to values reported by other investigators (Lennerstrand, 1974a; Waldeck et al., 1995).

The squirrel monkey lateral rectus muscle appeared to be approximately one-third the size of the cat lateral rectus muscle on visual examination during these studies. We are, at present, histologically examining the squirrel monkey lateral rectus muscle to determine average muscle fiber diameter, number, and type.

The change in stimulation frequency needed to increase tetanic tension by $1.0 \mathrm{mg}$ ( $\mathrm{kt}$ value) was determined for these units and found to be higher, on average, than it was in the cat $(\bar{x}=1.93$ vs 

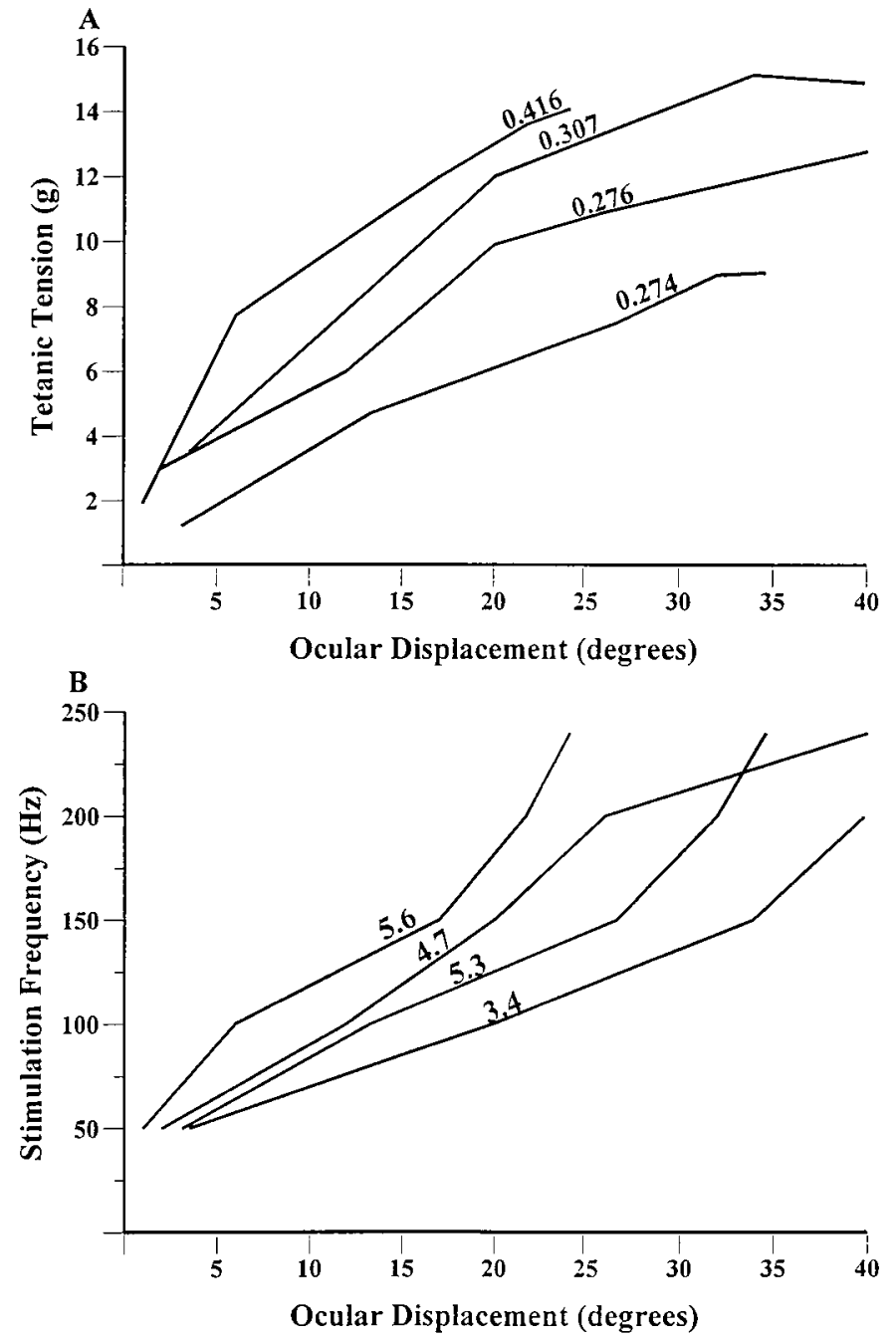

Figure 7. A, Whole lateral rectus muscle tetanic tension versus degree of eye movement in four animals. Note slope of tension change (grams) per degree for each animal with an average of $0.32 \mathrm{gm} /{ }^{\circ}$. $B$, Constant frequency stimulation delivered to the whole sixth nerve versus degree of eye movement in four animals. Note slope of frequency change per degree for each animal with an average of $4.7 \mathrm{~Hz} /{ }^{\circ}$.

$\overline{\mathrm{x}}=1.34)$. As in the cat, lower $\mathrm{kt}$ values in the primate were associated with more powerful units, whereas high kt units formed a clear population that consisted of weak units only (Fig. 4). In alert cats and primates, motoneurons with higher $K$ values (those showing a greater frequency change for $1^{\circ}$ changes in fixated eye position) appeared to be recruited later at more eccentric eye positions, but their force characteristics are unknown (Keller, 1981; Delgado-Garcia et al., 1986; Fuchs et al., 1988). We have suggested previously that if motoneuron $K$ value is directly related to motor unit $\mathrm{kt}$ value then powerful units might be recruited early in eye movements (Shall and Goldberg, 1992, 1995; Shall et al., 1996), but experiments that attempt a direct comparison of these measures (kt value and $\mathrm{K}$ value) have not yet been done. If a clear relationship were to be found, then investigators using behaving animals might be able to predict relative motor unit force from motoneuron $\mathrm{K}$ value alone.

\section{Hysteresis}

Are the motoneuron firing rates and force levels identical when the eye reaches a particular fixation point, regardless of the initial position of the eye? At the motor unit level, $75 \%$ of the units studied had an average tension (at a constant frequency of 100 $\mathrm{Hz}$ ) after the high-frequency pulse that was nearly double that seen with constant frequency stimulation alone. Twenty percent of the units had an average tension that was $\sim 42 \%$ less after the pulse than they did with constant frequency stimulation. In comparison, as the eye reached primary position from either the "on" or "off" field of a particular motoneuron, the average difference observed in motoneuron firing rate was $\sim 5 \%$ (Goldstein and Robinson, 1986). This firing rate inequality, at identical eye positions, was termed a motoneuron firing rate hysteresis (Eckmiller, 1974). We cannot yet be sure how the relatively small hysteresis in motoneuron firing rate correlates to the large single muscle unit force hysteresis, but the relationship does not appear to be linear. Continued examination of hysteresis in the precise eye movement system of the primate would seem warranted.

\section{Whole muscle}

Stimulation of the whole abducens nerve in the brainstem was done using $200 \mathrm{msec}$ stimulus trains with various constant frequencies (Fig. 6) to measure the resultant contractile forces as well as ocular displacements. The finding that an average of $\sim 320$ mg was needed to displace the eye by $1^{\circ}$ compares favorably with the $430 \mathrm{mg}$ that has been reported in humans during active contraction (Robinson et al., 1969), despite the obvious differences in eye size and mass. A change of $\sim 1.0 \mathrm{gm} /{ }^{\circ}$ has been noted in other studies (Fuchs and Luschei, 1971; Collins et al., 1981). In addition, it took an average frequency increase of $4.7 \mathrm{~Hz}$ to displace the eye $1^{\circ}$ in this study, and that value compares reasonably with the $7.5 \mathrm{~Hz} /{ }^{\circ}$ (although eye displacement was not measured directly) that can be approximated from the data presented by Fuchs and Luschei (1971) in the Maccaca mulatta.

The current whole-muscle force data $\left(320 \mathrm{mg} /{ }^{\circ}\right)$, when compared with the motor unit data $(\overline{\mathrm{x}}=186.2 \mathrm{mg}$ maximum tetanic tension), appears to indicate that as few as two or three motor units might be able to move the eye a full $1^{\circ}$.

\section{Motor units and the whole muscle}

We have previously shown in the cat ( 2.5 to $3.5 \mathrm{~kg}$ animals) lateral rectus muscle that the twitch and tetanic contractile forces elicited in response to stimulation of the whole abducens nerve are below what would be expected if one multiplied the average force of the motor units (i.e., twitch tension $\simeq 29.0 \mathrm{mg}$ and maximum tetanic tension $\simeq 194.0 \mathrm{mg}$ ) by the known number of lateral rectus motoneurons ( $n \simeq 1,100$ ) in the cat abducens nucleus (Shall and Goldberg, 1992; Goldberg et al., 1997b; Goldberg and Shall, 1997). In summary, $\sim 15.0 \mathrm{gm}$ of twitch force (Barmack et al., 1971; Goldberg et al., 1997b) and $\sim 110.0 \mathrm{gm}$ of tetanic force (Cooper and Eccles, 1930; Barmack et al., 1971; Goldberg and Shall, 1997) have been observed when, instead, one would "expect" $29.0 \mathrm{gm}$ of twitch force (Goldberg et al., 1997b) and 237.0 gm of tetanic force (Goldberg and Shall, 1997).

Possible reasons for the apparent loss of "expected" force, delineated above, need to be addressed. It has been shown that the cat lateral rectus muscle is composed of serially arranged and branching muscle fibers rather than having all its fibers arranged in parallel arrays (Mayr et al., 1975; Alvarado-Mallart and Pinçon-Raymond, 1976). Other investigators have speculated that such an arrangement could lead to a loss of expected force when the muscle contracts (Katz, 1939; Demieville and Partridge, 1980; Goldberg et al., 1997b). Other skeletal muscles have been shown to have serially arranged and interdigitated fibers as well, and 
such arrangements could significantly alter the contractile properties of a motor unit as it acts in concert with other units (Loeb et al., 1987; Ounjian et al., 1991; Roy et al., 1995; Trotter et al., 1995).

We now report an average $1.1 \mathrm{gm}$ of twitch force and $13.7 \mathrm{gm}$ of tetanic force in the squirrel monkey (0.7-1.1 $\mathrm{kg}$ animals) elicited by supramaximal stimulation of the whole abducens nerve. Similarly, whole-muscle maximum twitch and tetanic forces have been observed using nerve stimulation in larger primates. Fuchs and Luschei (1971) showed a $3.5 \mathrm{gm}$ twitch and an average of $57.0 \mathrm{gm}$ of tetanic force using 3-4 $\mathrm{kg}$ Maccaca mulattas, and in adult humans with motoneuron estimates of ５000 (Harley, 1942; Tomasch, 1973; Vijayashankar and Brody, 1977) tetanic forces were $<95$ gm during eye movements (Robinson et al., 1969; Collins et al., 1975, 1981). It appears then, that the whole-muscle forces in the current experiment are in line (adjusting for animal size) with what has been found previously in other primates.

It remains to be seen whether primate extraocular muscle will show nonparallel arrays of muscle fibers as found in the cat (Mayr et al., 1975; Alvarado-Mallart and Pinçon-Raymond, 1976) and whether the summation of motor unit forces will sum to equal the observed whole-muscle forces. In addition, we also may need to account for the pronounced hysteresis in single motor unit force. These possible intricacies in the final common pathway may cause us to reconsider how the precise motoneuronal firing patterns that have been observed in alert animals during eye movements are translated into stable and repeatable saccades, pursuit, and fixations.

\section{REFERENCES}

Alvarado-Mallart RM, Pinçon-Raymond M (1976) Nerve endings on the intramuscular tendons of cat extraocular muscles. Neurosci Lett 2:121-125.

Barmack NH, Bell CC, Rence BG (1971) Tension and rate of tension development during isometric responses of extraocular muscle. J Neurophysiol 34:1072-1079.

Binder-Macleod SA, Barrish WJ (1992) Force response of rat soleus muscle to variable-frequency train stimulation. J Neurophysiol 68:1068-1078.

Binder-Macleod SA, Clamann HP (1989) Force output of cat motor units stimulated with trains of linearly varying frequency. J Neurophysiol 61:208-217.

Burke RE (1981) Motor units: anatomy, physiology and functional organization. In: Handbook of physiology, Section 1, The nervous system, Vol II, Motor systems (Brooks VB, ed), pp 345-422. Bethesda: American Physiological Society.

Burke RE (1990) Motor unit types: some history and unsettled issues. In: The segmental motor system (Binder MD, Mendell LM, eds), pp 207-221. Oxford: Oxford UP.

Burke RE, Levine DN, Tsairis P, Zajac FE (1973) Physiological types and histochemical profiles in motor units of the cat gastrocnemius muscle. J Physiol (Lond) 234:723-748.

Collins CC, O'Meara D, Scott AB (1975) Muscle tension during unrestrained human eye movements. J Physiol (Lond) 245:351-369.

Collins CC, Carlson MR, Scott AB, Jampolsky A (1981) Extraocular muscle forces in normal human subjects. Invest Ophthalmol Vis Sci 20:652-664.

Cooper S, Eccles JC (1930) The isometric responses of mammalian muscles. J Physiol (Lond) 69:377-385.

Dean P (1996) Motor unit recruitment in a distributed model of extraocular muscle. J Neurophysiol 76:727-742.

Delgado-Garcia JM, del Pozo F, Baker R (1986) Behavior of neurons in the abducens nucleus of the alert cat-I. motoneurons. Neuroscience 17:929-952.

Demieville HN, Partridge LD (1980) Probability of peripheral interaction between motor units and implications for motor control. Am J Physiol 238:R119-R137.
Eckmiller R (1974) Hysteresis in the static characteristics of eye position coded in the alert monkey. Pflügers Arch 350:249-258.

Emmers R, Akert K (1963) A stereotaxic atlas of the brain of the squirrel monkey (Saimiri Sciureus). Madison: University of Wisconsin.

Fuchs AF, Luschei ES (1970) Firing patterns of abducens neurons of alert monkeys in relationship to horizontal eye movement. J Neurophysiol 33:382-392.

Fuchs AF, Luschei ES (1971) Development of isometric tension in simian extraocular muscle. J Physiol (Lond) 219:155-166.

Fuchs AF, Kaneko CRS, Scudder CA (1985) Brainstem control of saccadic eye movements. Annu Rev Neurosci 8:307-337.

Fuchs AF, Scudder CA, Kaneko CRS (1988) Discharge patterns and recruitment order of identified motoneurons and internuclear neurons in the monkey abducens nucleus. J Neurophysiol 60:1874-1895.

Goldberg ME, Segraves MA (1989) The visual and frontal cortices. In: The neurobiology of saccadic eye movements (Wurtz RH, Goldberg ME, eds), pp 283-313. Amsterdam: Elsevier.

Goldberg SJ (1990) Mechanical properties of extraocular motor units. In: The segmental motor system (Binder MD, Mendell LM, eds), pp 222-238. Oxford: Oxford UP.

Goldberg SJ, Shall MS (1997) Lateral rectus whole muscle and motor unit contractile measures with the extraocular muscles intact. J Neurosci Methods 78:47-50.

Goldberg SJ, Lennerstrand G, Hull CD (1976) Motor unit responses in the lateral rectus muscle of the cat: intracellular current injection of abducens nucleus neurons. Acta Physiol Scand 96:58-63.

Goldberg SJ, McClung JR, Shall MS (1997a) Lateral rectus whole muscle and single motor unit contractile characteristics in the primate. Soc Neurosci Abstr 23:1302.

Goldberg SJ, Wilson KE, Shall MS (1997b) Summation of extraocular motor unit tensions in the lateral rectus muscle of the cat. Muscle Nerve 20:1229-1235.

Goldberg SJ, McClung JR, Meredith, MA, Shall MS (1998) Eye movement and force generated by primate lateral rectus whole muscle and motor units. Invest Ophthalmol Vis Sci 39:S768.

Goldstein HP, Robinson DA (1986) Hysteresis and slow drift in abducens unit activity. J Neurophysiol 55:1044-1056.

Harley RD (1942) A quantitative study of the cells and fibers in the nucleus: nerve complexes of the fourth and sixth cranial nerves. Am J Ophthalmol 25:1029-1042.

Judge SJ, Richmond B, Chu FS (1980) Implantation of magnetic search coils for measurement of eye position: an improved method. Vision Res 20:535-538.

Katz B (1939) The relation between force and speed in muscular contraction. J Physiol (Lond) 96:45-64.

Keller EL (1981) Oculomotor neuron behavior. In: Models of oculomotor behavior and control (Zuber BL, ed), pp 1-19. Boca Raton, FL: CRC.

Lennerstrand G (1974a) Electrical activity and isometric tension in motor units of the cat's inferior oblique muscle. Acta Physiol Scand 91:458-474.

Lennerstrand G (1974b) Mechanical studies on the retractor bulbi muscle and its motor units in the cat. J Physiol (Lond) 236:43-55.

Loeb GE, Pratt CA, Chanaud CM, Richmond FJR (1987) Distribution and innervation of short, interdigitated muscle fibers in parallel-fibered muscles of the cat hindlimb. J Morphol 191:1-15.

Lucas CA, Hoh JFY (1997) Extraocular fast myosin heavy chain expression in the levator palpebrae and retractor bulbi muscles. Invest Ophthalmol Vis Sci 38:2817-2825.

Macefield VG, Fuglevand AJ, Bigland-Ritchie B (1996) Contractile properties of single motor units in human toe extensors assessed by intraneural motor axon stimulation. J Neurophysiol 75:2509-2519.

Mayr R, Gottschall J, Gruber H, Neuhuber W (1975) Internal structure of cat extraocular muscle. Anat Embryol 148:25-34.

Meredith MA, Goldberg SJ (1986) Contractile differences between muscle units in the medial rectus and lateral rectus muscles in the cat. J Neurophysiol 56:50-62.

Moschovakis AK, Scudder CA, Highstein SM (1996) The microscopic anatomy and physiology of the mammalian saccadic system. Prog Neurobiol 50:133-254.

Nelson JS, Goldberg SJ, McClung JR (1986) Motoneuron electrophysiological and muscle contractile properties of superior oblique motor units in the cat. J Neurophysiol 55:715-726.

Ounjian M, Roy RR, Eldred E, Garfinkel A, Payne JR, Armstrong A, 
Toga AW, Edgerton VR (1991) Physiological and developmental implications of motor unit anatomy. J Neurobiol 22:547-559.

Remmel RS (1980) An inexpensive eye movement monitor using the scleral search coil technique. IEEE Trans Biomed Eng 4:388-390.

Robinson DA (1981) The use of control systems analysis in the neurophysiology of eye movements. Annu Rev Neurosci 4:463-503.

Robinson DA, O'Meara DM, Scott AB, Collins CC (1969) Mechanical components of human eye movements. J Appl Physiol 26:548-553.

Roy RR, Garfinkel A, Ounjian M, Payne J, Hirahara A, Hsu E, Edgerton VR (1995) Three-dimensional structure of cat tibialis anterior motor units. Muscle Nerve 18:1187-1195.

Shall MS, Goldberg SJ (1992) Extraocular motor units: type classification and motoneuron stimulation frequency-muscle unit force relationships. Brain Res 587:291-300.

Shall MS, Goldberg SJ (1995) Lateral rectus EMG and contractile responses elicited by cat abducens motoneurons. Muscle Nerve 18:948-955.

Shall MS, Sorg PJ, McClung JR, Gilliam EE, Goldberg SJ (1995) Relationship of the mechanical properties of the cat inferior oblique muscle to the anatomy of its motoneurons and nerve branches. Acta Anat 153:151-160.
Shall MS, Wilson KE, Goldberg SJ (1996) Extraocular motoneuron stimulation frequency effects on motor unit tension in cat. Acta Anat 157:217-225.

Sparks DL (1986) Translation of sensory signals into commands for control of saccadic eye movements: role of primate superior colliculus. Physiol Rev 66:118-171.

Spencer RF, Porter JD (1988) Structural organization of the extraocular muscles. in: Neuroanatomy of the oculomotor system (Buttner-Ennever JA, ed), pp 33-79. Amsterdam: Elsevier.

Tomasch J (1973) Cell frequencies in the abducens nucleus of man. Confin Neurol 35:257-262.

Trotter JA, Richmond FJR, Purslow PP (1995) Functional morphology and motor control of series-fibered muscles. In: Exercise and sports sciences reviews, Vol 23 (Hollizy J, ed), pp 167-213. Baltimore: William and Wilkins.

Vijayashankar N, Brody H (1977) A study of aging in the human abducens nucleus. J Comp Neurol 173:433-438.

Waldeck RF, Murphy EH, Pinter MJ (1995) Properties of motor units after self-reinnervation of the cat superior oblique muscle. J Neurophysiol 74:2309-2318. 